\title{
GLUCOSE UTILIZATION BY THE MYOMETRIUM DURING EARLY PSEUDOPREGNANCY IN THE RAT
}

\author{
J. M. YOCHIM AND R. J. SALDARINI* \\ Department of Biochemistry and Physiology, \\ University of Kansas, Lawrence, Kansas 66044, U.S.A. \\ (Received 31st October 1968, revised 10th February 1969)
}

\begin{abstract}
Summary. In vitro incorporation of $\left[\mathrm{U}-{ }^{14} \mathrm{C}\right]$ glucose into the myometrium of the rat was measured during the oestrous cycle and early pseudopregnancy. Labelled glucose was metabolized primarily to $\mathrm{CO}_{2}$, extracellular lactate and intracellular acid-soluble material. The specific activity of lactate produced after incubation was higher during oestrus and metoestrus than at other times of the oestrous cycle. During Days 0 to 1 of pseudopregnancy the specific activity of lactate decreased, a reflection of an increased utilization of endogenous substrate. During Days 1 to 4 of pseudopregnancy a gradual rise in glucose uptake occurred. Oestrone, in low (permissive) doses, did not stimulate glucose incorporation above that found in ovariectomized rats, but did block a stimulatory action of progesterone. Similarly, the specific activity of lactate produced during the incubation was increased ten-fold during a 5-day period of progesterone treatment. Oestrogen blocked this action of progesterone, reducing the response to the level observed in intact pseudopregnant rats. The increased dependence upon exogenous glucose for metabolism during early progestation may be a reflection of an action of progesterone on the myometrium which tends to deplete glycogen stores and other endogenous substrates more rapidly than they can be restored by permissive levels of oestrogen.
\end{abstract}

\section{INTRODUGTION}

In studies of the physiology of the uterus of the rat during pseudopregnancy (Saldarini \& Yochim, 1968), it was noted that the character of endometrial metabolism changed gradually from that of anaerobiosis, with rapid utilization of endogenous substrate, to aerobiosis, with increased utilization of exogenous material. Glucose incorporation was stimulated by progesterone, and reached a peak on the 4th day of pseudopregnancy. Oestrone blocked this response at low (permissive) doses which, when given alone, were insufficient to stimulate glucose uptake above that found in ovariectomized rats.

Because of the different physiological rôles of the endometrium and the myometrium and the dominant rôle of anaerobiosis in myometrial activity

* Present address: Department of Anatomy, Brain Research Institute, U.C.L.A. School of Medicine, Los Angeles, California 90024. 
(Kerly, 1937, 1940), it was of interest to study the carbohydrate metabolism of the myometrium during the pre-implantation period, a time of transition from strong mechanical activity after ovulation to relative quiescence during implantation. Experiments were carried out to study glucose utilization in the myometrium of the rat during early pseudopregnancy, and its regulation by ovarian steroids at dose levels which can maintain other parameters of progestation during this time (Saldarini \& Yochim, 1967).

\section{MATERIALS AND METHODS}

Animals

Adult, female rats (200 to $250 \mathrm{~g}$ ) of the Holtzman strain (Sprague-Dawley derived) were housed in individual cages in air-conditioned quarters at 20 to $23^{\circ} \mathrm{C}$ and a light régime of 14-hr fluorescent illumination and 10-hr darkness/day. The midpoints of the light and dark phases occurred at 12.00 and 24.00 hours, respectively. All animals were allowed free access to Purina Lab Chow and water and vaginal smears of each rat were recorded daily for two or three cycles before use.

Pseudopregnancy was induced by mechanical stimulation of the uterine cervix during pro-oestrus and oestrus. Day 0 of pseudopregnancy was designated as the last day of vaginal cornification (oestrus); Day 1 was recorded as the first day of leucocytic infiltration of the vagina.

\section{Experimental design and hormone treatment}

All experiments were started on Day 0 of pseudopregnancy. Oestrone, progesterone, or a combination of these steroids, were injected subcutaneously in $0.1 \mathrm{ml}$ sesame oil each day from the time of ovariectomy (Day 0 ) until the animals were killed. In order to approximate hormonal conditions which mimicked physiological responses in intact rats (Saldarini \& Yochim, 1967), measurements of the amount of $\left[\mathrm{U}-{ }^{14} \mathrm{C}\right]$ glucose incorporated into the extracellular lactate, carbon dioxide, intracellular acid-soluble and residual fractions of myometrium were made in five experiments involving ovariectomy (Day 0 ) and replacement with: (1) no hormones, (2) $1.0 \mu \mathrm{g}$ oestrone daily, (3) $1.0 \mathrm{mg}$ progesterone on Day $0,2.0 \mathrm{mg}$ daily thereafter, (4) a combination of treatments (2) and (3), (5) $1.0 \mu \mathrm{g}$ oestrone and $1.0 \mathrm{mg}$ progesterone on Day $0 ; 0.5 \mu \mathrm{g}$ oestrone and $2.0 \mathrm{mg}$ progesterone daily thereafter. The only difference between Exps. 4 and 5 was the dosage of oestrone injected with progesterone after Day 0. However, since no significant differences existed between the results of Exps. 4 and 5, the combined data are presented.

\section{Measurement of glucose utilization}

All animals were used between 09.00 and 12.00 hours. After anaesthesia was induced with ether, each rat was weighed and killed by cervical dislocation. The uterus was removed quickly and transferred to an ice-cold Petri dish lined with filter paper saturated with Krebs-Ringer-phosphate buffer. Each uterine horn was trimmed of adhering fat and mesentery and weighed to the nearest $0.1 \mathrm{mg}$ on a torsion balance. The horns were split longitudinally and the 


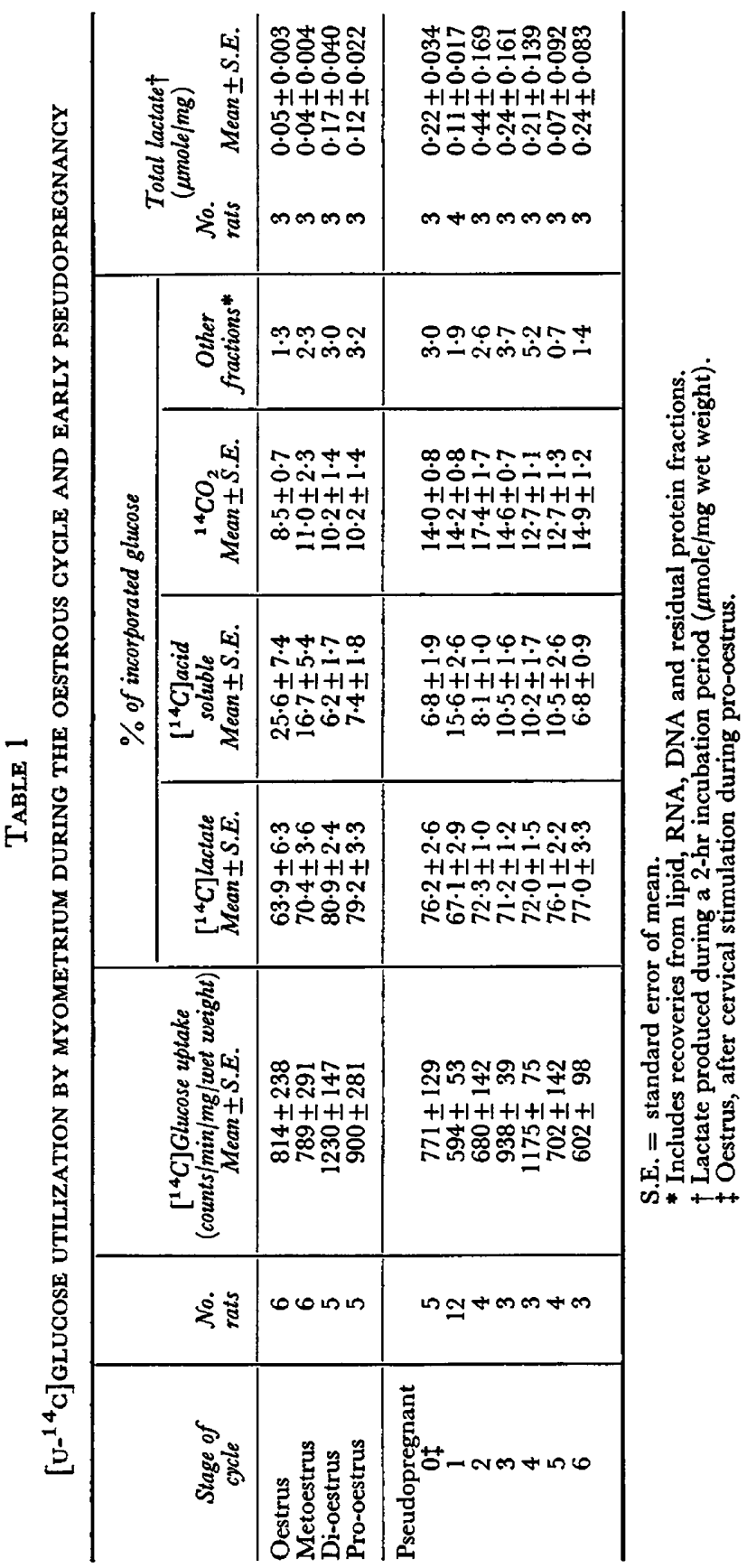


endometrium and sub-endometrial stroma were scraped gently from each horn. Representative portions ( 30 to $50 \mathrm{mg}$ ) of myometrium were taken from each horn and sliced longitudinally on a Stadie-Riggs tissue slicer. The myometrial slices were placed in ice-cold, 25-ml Erlenmeyer flasks containing $2.0 \mathrm{ml}$ of Krebs-Ringer-phosphate buffer ( $\mathrm{pH} 7 \cdot 4)$. The flasks were sealed and placed in a Warburg agitator at $37.5^{\circ} \mathrm{C}$. After exposing the contents of the flasks to an atmosphere of $100 \%$ oxygen for $8 \mathrm{~min},\left[\mathrm{U}-{ }^{14} \mathrm{C}\right]$ glucose $(0.1 \mathrm{ml}$, $5.007 \mu$ mole, $1.25 \mu \mathrm{Ci})$ was injected into each vessel. An aliquot $(0.05 \mathrm{ml})$ of the medium was removed immediately for determination of the specific activity of glucose. This ranged between 0.9 and $1.1 \times 10^{6}$ counts $/ \mathrm{min} / 5.007$ $\mu$ mole in $2.1 \mathrm{ml}$ buffer.

Procedures for the 2-hr incubation, extraction, recovery and measurement of the fractions were identical to those reported previously (Saldarini \& Yochim, 1968).

Isotope fractions are described in the present report in two ways: (a) counts/ $\mathrm{min} / \mathrm{mg}$ wet weight, (b) $\%$ of incorporated labelled glucose. About $10 \%$ of the radio-activity injected into the flask could not be accounted for in recovery calculations.

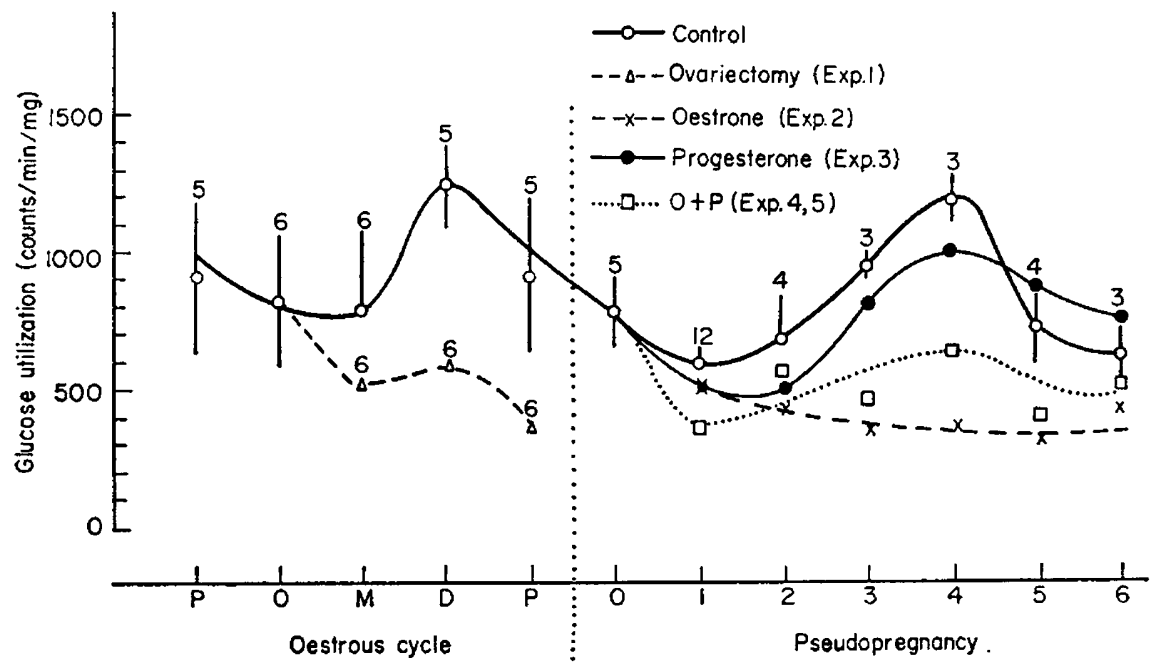

TexT-FIG. 1. Utilization of $\left[\mathrm{U}-{ }^{14} \mathrm{C}\right]$ glucose by myometrium during the oestrous cycle and early pseudopregnancy. Exp. 1: ovariectomized rats; Exp. 2: oestrone, 1.0 $\mu \mathrm{g}$ /day; Exp. 3: progesterone, $1.0 \mathrm{mg}$ on Day 0 (oestrus), $2.0 \mathrm{mg}$ daily thereafter; Exps. 4, 5: progesterone daily with either $0.5 \mu \mathrm{g}$ or $1.0 \mu \mathrm{g}$ oestrone. S.E. and number of rats listed for control and ovariectomized rats. Number of rats in Exps. 2, 3, 4, and $5=$ three rats/ point. $\mathbf{P}=$ pro-oestrus, $\mathrm{O}=$ oestrus, $M=$ metoestrus, $\mathrm{D}=$ di-oestrus.

\section{RESULTS}

Control studies-oestrous cycle and pseudopregnancy

Although changes in the rate of glucose incorporation by myometrial slices were observed during the oestrous cycle (Table 1, Text-fig. 1), they were not significant. In contrast, during pseudopregnancy glucose incorporation was 
much more reproducible, and increased gradually from Day 1 to a peak on Day $4(P<0.001)$. After Day 4 , a decrease in glucose incorporation occurred.

Production of labelled $\mathrm{CO}_{2}$ by the myometrium accounted for about 8 to $17 \%$ of the utilized glucose (Table 1). During the cycle, no significant changes in percentage ${ }^{14} \mathrm{CO}_{2}$ were measured: the average production accounted for about $10 \%$. However, after the induction of pseudopregnancy, the fraction of labelled $\mathrm{CO}_{2}$ increased significantly to a peak of $17 \%$ on Day 2 . The response during oestrus (Day 0 ) after cervical stimulation was greater than that measured during normal oestrus $(P<0.001)$.

Of the labelled glucose incorporated, about 60 to $80 \%$ appeared as $\left[{ }^{14} \mathrm{C}\right]$ lactate and about 6 to $26 \%$ as acid-soluble material (Table 1). During the

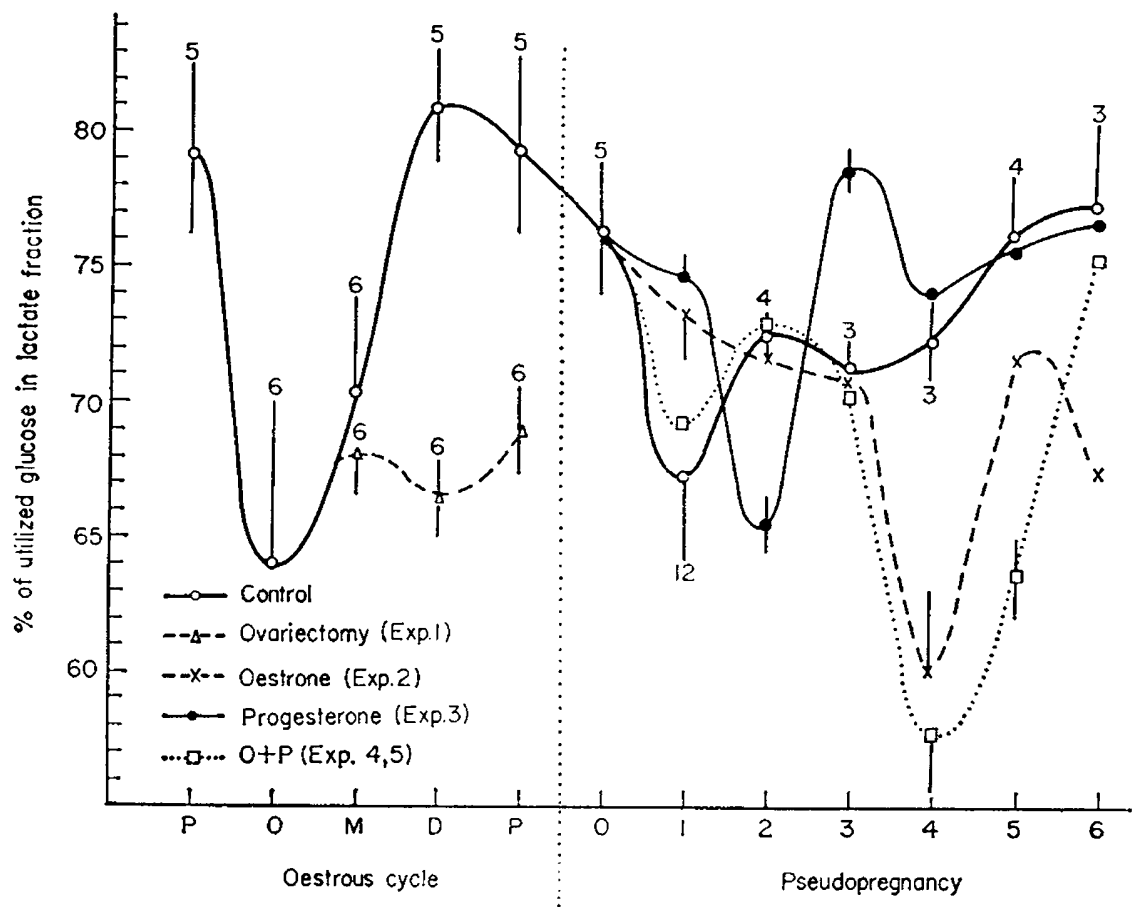

Text-pIg. 2. Percentage of utilized [U- $\left.{ }^{14} \mathrm{C}\right]$ glucose which appeared as labelled lactate after incubation of myometrium from rats during the oestrous cycle and pseudopregnancy. Exp. 1: ovariectomized rats; Exp. 2: oestrone, $1.0 \mu \mathrm{g} /$ day; Exp. 3: progesterone, $1.0 \mathrm{mg}$ on Day $0,2.0 \mathrm{mg}$ daily thereafter; Exps. 4, 5: progesterone daily with either $0.5 \mu \mathrm{g}$ or 1.0 $\mu \mathrm{g}$ oestrone. Number of rats depicted above or below S.E. in control experiments. Number of rats in Exps. 2, 3, 4 and $5=$ three rats/point.

oestrous cycle, the amount of labelled material in the lactate fraction increased between oestrus and di-oestrus $(P<0.05)$ and decreased thereafter (Text-fig. 2). In pseudopregnancy, the amount of labelled material recovered as $\left[{ }^{14} \mathrm{C}\right]$ lactate decreased to about $67 \%$ of the incorporate glucose by Day $1(P<0.05)$. Changes in the amount of labelled material in the acid-soluble fraction were inversely related to those of lactate (Table 1).

A determination of total extracellular lactate in the 2-hr incubation period (Table 1) revealed peak accumulation of this product during the periods of 
di-oestrus and pro-oestrus, followed by a significant decrease fafter ovulation $(P<0.05)$. By contrast, during oestrus (Day 0$)$ and Day 1 after cervical stimulation, lactate production remained elevated. The production of lactate during Days 2 to 6 of pseudopregnancy was relatively high, but variable (Table 1).

An estimation of the extent to which exogenous (labelled) material contributed to the lactate pool is depicted in Text-fig. 3. During the oestrous cycle, peak contribution to the pool from labelled glucose occurred during oestrus and metoestrus. Relatively less label was incorporated as lactate during Days 0 to 1

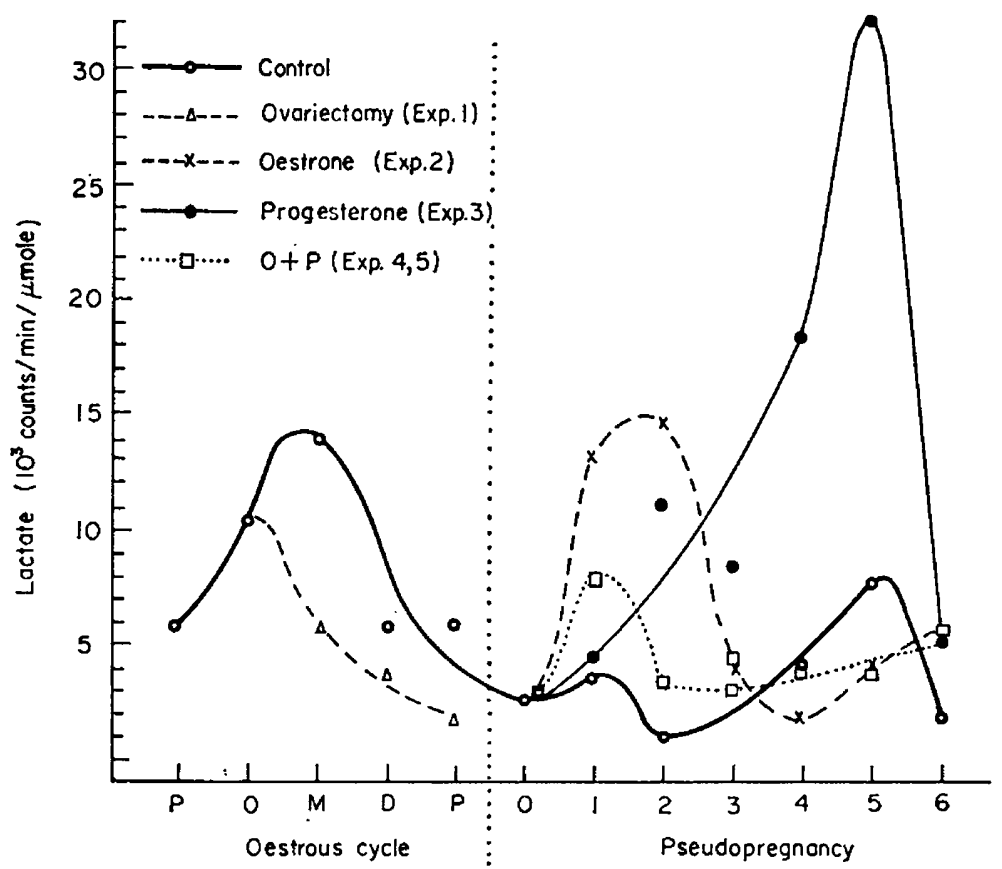

TEXT-FIG. 3. The specific activity of lactate $\left(\left[{ }^{14} \mathrm{C}\right]\right.$ lactate/total extracellular lactate production) in myometrium. Exp. 2: oestrone, 1.0 $\mu \mathrm{g}$ daily; Exp. 3: progesterone, $1.0 \mathrm{mg}$ on Day 0, 2.0 mg daily thereafter; Exps. 4, 5: progesterone daily with either $0.5 \mu \mathrm{g}$ or $1.0 \mu \mathrm{g}$ oestrone. This plot illustrates the extent to which exogenous substrate contributed to the production of lactate by myometrial tissue. Note the dilution of label which occurred during Days 0 to $l$ of pseudopregnancy in contrast to the high specific activity during the oestrous-metoestrous interval.

of pseudopregnancy. From Days 2 to 5 , a seven-fold increase in the specific activity of lactate was noted.

\section{Experimental studies—ovariectomy and hormone replacement}

Ovariectomy and replacement with daily injections of $1.0 \mu \mathrm{g}$ oestrone (Exp. 2) resulted in glucose incorporation which was significantly less than that measured in intact, pseudopregnant rats. The response (between 300 to 500 counts $/ \mathrm{min} / \mathrm{mg}$ ) was similar to that measured in Exp. 1, the untreated ovariectomized animals (Text-fig. 1).

Treatment with progesterone (Exp. 3) caused changes which were similar to those measured in intact rats during early pseudopregnancy. However, when 
oestrone and progesterone were administered together (Exps. 4 and 5), it was noted that oestrogen prevented in part the progesterone-induced incorporation. Glucose uptake was intermediate between the responses observed with either steroid alone, about 400 to 700 counts $/ \mathrm{min} / \mathrm{mg}$ (Text-fig. 1).

Of the glucose incorporated, a variable amount was recovered as labelled lactate after oestrogen treatment (Exp. 2). Incorporation decreased transiently from $73 \%$ on Day 1 to about $60 \%$ on Day $4(P<0.05$, Text-fig. 2). After treatment with progesterone (Exp. 3), $\left[{ }^{14} \mathrm{C}\right]$ lactate decreased to $65 \%$ on Day 2, with a 'rebound' peak of about $79 \%$ on Day 3. After Day 3, the incorporation of label into lactate paralleled that observed in intact pseudopregnant rats (Text-fig. 2). When both steroids were administered simultaneously (Exps. 4 and 5), it was noted that the labelled lactate fraction during Days 1 to 3 mimicked the pattern in intact rats. During Days 4 to 6 , the response was similar to that of rats treated with oestrogen (Text-fig. 2).

The effects of steroid hormone treatments on the specific activity of lactate are depicted in Text-fig. 3. With oestrogen treatment (Exp. 2) the ratio of $\left[{ }^{14} \mathrm{C}\right]$ lactate:total lactate increased from $3 \times 10^{3}$ counts $/ \mathrm{min} / \mu$ mole to about $15 \times 10^{3}$ counts $/ \mathrm{min} / \mu$ mole on Day 2 . Thereafter, the relative amount of labelled material appearing as lactate declined. Daily injection of progesterone (Exp. 3) caused a ten-fold rise in specific activity to a peak of $32 \times 10^{3}$ counts $/ \mathrm{min} / \mu \mathrm{mole}$ on Day 5, followed by a rapid decline. Administration of the steroid combinations (Exp. 4 and 5) produced a curious effect: during Days 1 and 2, the progesterone component appeared to block the oestrogen-stimulated peak, and during Days 3 to 5, the oestrogen component blocked the progesteroneinduced peak. The result was a pattern similar in part to that observed in intact pseudopregnant rats.

\section{DISCUSSION}

During the follicular phase of the oestrous cycle, the myometrium utilizes to an increasing extent an endogenous store of substrate which contributes to the lactate pool (Text-fig. 3) and, perhaps, to the observed changes in oxidative metabolism as well (Saldarini \& Yochim, 1967). The gradually increased rate of glycogen synthesis and turnover which occurs in the uterus during this period could provide ample endogenous substrate for both anaerobic and oxidative metabolism, and would be consistent with the present data (Boettiger, 1946; Rosenbaum \& Goolsby, 1957; Kostyo, 1957; Rubulis, Jacobs \& Hughes, 1965).

After ovulation, during oestrogen deprivation, the myometrium relies to a greater degree upon exogenous substrate (Text-fig. 3), perhaps because of a relative deficiency of glycogen (Boettiger, 1946; Kostyo, 1957; Rubulis et al., 1965; Moulton \& Leonard, 1966) or other non-carbohydrate substrates. That less glucose is converted to lactate during this time (Text-fig. 2, Table 1), may be an indication of the general decline in metabolic activity which occurs after ovulation or during oestrogen deprivation (Kerly, 1937, 1940; Saldarini \& Yochim, 1967; Khayyal \& Scott, 1935a, b).

On Day 0 of pseudopregnancy, 1 day after cervical stimulation, the meta- 
bolism of the myometrium was altered significantly from that during oestrus on the equivalent day of the oestrous cycle. Although the rate of glucose uptake remained stable, endogenous substrate was mobilized to greater degree than during oestrus, resulting in an increased lactate production (Table 1, Textfig. 3). Such changes are consistent with the observed depletion of glycogen stores at this time (Boettiger, 1946; Kostyo, 1957), and may be the result of a transiently increased ovarian steroid secretion, induced by the release of $\mathbf{L H}$ which has been shown to occur after a copulatory stimulus (Taleisnik, Caligaris \& Astrada, 1966).

During Days 1 to 4 of pseudopregnancy, a gradual increase in glucose uptake, and in the specific activity of lactate was measured (Text-figs. 1 and 3). These data may be a reflection of a continued deficiency of endogenous substrate in the myometrium during pseudopregnancy (Boettiger, 1946, Connolly, Bitman, Cecil \& Wrenn, 1962) and of a possible requirement, therefore, for increased glucose uptake which is used for both glycolytic and oxidative purposes (Saldarini \& Yochim, 1967, 1968).

Thus, the present study indicates that, during early pseudopregnancy, a relative shift in metabolism of the myometrium occurs, from utilization of endogenous substrate (glycogen or protein) to utilization of exogenous substrate. The metabolism of glucose by this tissue appears to be similar to that in the endometrium (Saldarini \& Yochim, 1968).

Treatment with ovarian steroid hormones produced responses which warrant conclusions similar to those for the endometrium (Saldarini \& Yochim, 1968): (a) glucose incorporation was stimulated by progesterone but not oestrone at the doses used, although the latter blocked the action of progesterone (Textfig. 1); (b) permissive doses of oestrone decreased the amount of labelled material incorporated into lactate on Day 4, a response which was not blocked when progesterone was administered with the oestrogen (Text-fig. 2); (c) progesterone increased the specific activity of the total lactate, and (d) oestrogen blocked the action of progesterone, reducing the response to a level similar to that in intact rats (Text-fig. 3).

Although not directly comparable because of differences in experimental design, the present results warrant conclusions similar to those reported by Walaas, Walaas \& Löken (1952) and Szego \& Roberts (1953). These workers showed that oestrogen, administered to long-term ovariectomized rats, stimulated an increase in glucose uptake and lactate production, an increased turnover of endogenous substrate, and an increase in oxygen consumption. From the present study, it is evident that permissive levels of oestrogen, administered to maintain minimal stimulation, can modify the myometrial metabolic activity in a similar fashion but without increasing glucose uptake above that found in ovariectomized rats (Text-figs. 1 and 3 ).

A general interpretation of the endocrinology of the early luteal phase may also be derived from these data. From Text-fig. 3, it might be concluded that during the first 6 days of pseudopregnancy in the rat both hormones are secreted continuously, since, with either steroid alone, the response does not parallel the normal pattern. Text-fig. 2 reveals that, if both steroids are secreted continuously, the level of oestrogen secretion during Days 4 to 6 must be very low, 
in order not to block progestagen action. The data from Text-fig. 1 reveal that the ratio of oestrogen: progestagen in intact pseudopregnant rats must be somewhat less than that used in the present study.

Thus, the gradual shift from strong oestrogen dominance during the time of ovulation to progestagen dominance with low, permissive oestrogen activity during the time of implantation results in a gradually increased utilization of exogenous substrate by the myometrium. This change, perhaps due to a glycogenolytic action of progesterone (Rosenbaum \& Goolsby, 1957; Brody \& Westman, 1958), is consistent with the concept of a 'quiescent' uterus in which both glucose and oxygen are readily available for metabolism, although endogenous substrate may be limited.

\section{ACKNOWLEDGMENTS}

This research was supported in part by funds from an Institutional Grant, American Cancer Society, and by a Biomedical Research Grant, University of Kansas.

We wish to thank Dr Preston Perlman, Schering Corporation, for providing crystalline oestrone and progesterone for this study.

\section{REFERENCES}

Boetriger, E. G. (1946) Changes in the glycogen and water content of the rat uterus. F. cell. comp. Physiol. 27, 9.

BRODY, S. \& WESTMAN, A. (1958) Effects of oestradiol and progesterone on the glycogen content of the rabbit uterus. Acta endocr., Copenh. 28, 39.

Connolly, M. C., Bitman, J., Cecil, H. C. \& Wrenn, T. R. (1962) Water, electrolyte, glycogen and histamine content of the rat uterus during pregnancy. Am. F. Physiol. 203, 717.

KERLy, M. (1937) The effect of the oestrous cycle on the metabolism of the isolated rat uterus. Biochem. f. 31, 1544.

KerLy, M. (1940) The effect of estrone on the metabolism of the rat uterus. Biochem. F. 34, 814.

Khayyal, M. A. \& Scotr, C. M. (1935a) The oxygen consumption of the isolated uterus of the rat and mouse. Q.Fl exp. Physiol. 24, 249.

Khayyal, M. A. \& Scott, C. M. (1935b) The effect of ovarian extracts on the oxygen consumption of the uterus. Q.Fl exp. Physiol. 25, 77.

Kosryo, J. L. (1957) A study of the glycogen levels of the rat uterus and certain skeletal muscles during pregnancy. Endocrinology, 60, 33.

Moulton, B. C. \& Leonard, S. L. (1966) Phosphorylase activity in the pseudopregnant rat uterus. Endocrinology, 78, 838.

Rosenbaum, R. M. \& Goolsey, C. M. (1957) The histochemical demonstration of hormonally controlled, intracellular glycogen in the endometrium of the rat. F. Histochem. Cytochem. 5, 33.

Rubulis, A., Jacons, R. D. \& Hughes, E. C. (1965) Glycogen synthetase in mammalian uterus. Biochim. biophys. Acta, 99, 584.

SAldarini, R. J. \& Yochim, J. M. (1967) Metabolism of the uterus of the rat during early pseudopregnancy and its regulation by estrogen and progestogen. Endocrinology, 80, 453.

SAldarini, R. J. \& Yochim, J. M. (1968) Glucose utilization by endometrium of the uterus of the rat during early pseudopregnancy and its regulation by estrogen and progestogen. Endocrinology, 82, 511.

Szego, C. M. \& Roberts, S. (1953) Steroid action and interaction in uterine metabolism. Recent Prog. Horm. Res. 8, 419.

Taleisnik, S., Galigaris, L. \& Astrada, J. J. (1966) Effect of copulation on the release of pituitary gonadotropins in male and female rats. Endocrinology, 79, 49.

WalaAs, O., WalaAs, E. \& LöKEn, F. (1952) Effect of oestradiol monobenzoate on the metabolism of rat uterine muscle. Acta endocr., Copenh. 10, 201. 